\title{
¿NADA EN BIOLOGÍA TIENE SENTIDO SI NO ES A LA LUZ DE LA EVOLUCIÓN?
}

\section{Does nothing in Biology make sense except in the light of evolution?}

\author{
Julio Alejandro Castro Moreno ${ }^{1}$
}

Resumen: Se critica la pertinencia de la famosa frase de Dobzhansky "Nada tiene sentido en biología si no es a la luz de la evolución", la cual denominamos como el Dogma Central de la Síntesis Evolutiva (DCSE). En la primera sección se explica el origen del DCSE y se retoman los puntos centrales del artículo en el que Dobzhansky lo propuso. En el segundo apartado se desarrollan tres puntos: se hace una reflexión sobre cómo el trabajo científico de dicho autor pone en aprietos la idea de Mayr acerca de que existen "dos biologías"; se cuestiona en qué medida es factible sostener que la columna vertebral de la biología es la evolución; y se plantean algunas implicaciones del DCSE en la filosofía y en la didáctica de la biología. En las conclusiones se argumenta por qué el DCSE debe ser abandonado de una vez por todas.

Palabras clave: Theodosius Dobzhansky. Evolución. Creacionismo. Dogma. Darwinismo.

\begin{abstract}
We criticize the relevance of Dobzhansky's famous phrase "Nothing in biology makes sense except in the light of evolution", which we call the Central Dogma of the Evolutionary Synthesis (DCSE by its initials in Spanish). The first section explains the origin of DCSE and takes up the main points of the article in which Dobzhansky proposed it. The second section develops three points: Does a reflection of how Dobzhansky's scientific work contradict Mayr's idea that there are "two biologies"? To what extent it is feasible to argue that the biology's backbone is evolution? And it then discusses some implications of DCSE for biology's philosophy and didactics. The conclusions argue that DCSE should be abandoned once and for all.
\end{abstract}

Keywords: Theodosius Dobzhansky. Evolution. Creationism. Dogma. Darwinism.

\footnotetext{
${ }^{1}$ Universidad Pedagógica Nacional (UPN), Departamento de Biología, Bogotá, Colombia. Dirección postal: Calle 72 \# 11-86, edificio B, oficina 314, Bogotá, Colombia. E-mail: jcastro@pedagogica.edu.co; alecasmor@yahoo.es
} 
Un conocimiento profundo del darwinismo nos enseña a ser prudentes con respecto a la fácil asunción de que el diseño es la única alternativa a la casualidad y nos enseña a buscar escalas graduadas de complejidad incrementadas poco a poco. Antes que Darwin, filósofos como Hume comprendieron que la improbabilidad de la vida no significaba que hubiera sido diseñada, pero no podían imaginar cuál era la alternativa. Tras Darwin, deberíamos presentir ciertas sospechas en lo más profundo de nuestro ser, con relación a la propia idea de diseño. La ilusión del diseño es una trampa que nos capturó con anterioridad, y Darwin debería habernos inmunizado mediante la mejora de nuestra conciencia. Debería haber tenido éxito con todos nosotros. (DAWKINS, 2007, p. 125)

\section{Introducción: la Biología y sus dogmas}

En la biología (y tal vez en otras ciencias) se han empleado frases, a manera de eslóganes, que en cierto modo han hecho historia. Por un lado, debido a su estrepitosa caída, al demostrarse que son afirmaciones falsas o, por otro lado, porque se han incrustado férreamente en el imaginario de los científicos y del público en general. Para ilustrar la primera situación traigo a colación dos ejemplos.

A inicios de la década de 1960, Jaques Monod y su colega François Jacob postularon el modelo del operón Lac, para explicar de qué manera se regula la información genética en el metabolismo de la lactosa en la bacteria Escherichia coli. Monod creía, equivocadamente, que "lo que es cierto para el colibacilo lo es para el elefante." (JACOB, 1989, p. 294). Ésta es otra forma de decir que ése es el modelo para explicar todo tipo de regulación génica en todos los organismos vivos. Investigaciones en otros procesos reguladores para otros procesos metabólicos y en diferentes organismos (principalmente en bacterias), demostraron que no existía tal modelo único. Así, entonces, el eslogan de Monod tuvo una vida muy corta.

Mi segundo ejemplo es el "Dogma central de la biología molecular", propuesto por Francis Crick (1958, p. 153), quien lo articuló entre 1958 y 1970, el cual sostenía que la información genética sólo puede ir en una dirección: $\mathrm{ADN} \rightarrow \mathrm{ARN}_{\mathrm{m}}$ (transcripción) $\rightarrow$ Proteínas (traducción). Este dogma también tuvo una existencia efímera, debido, fundamentalmente, al hallazgo de la enzima transcriptasa inversa, presente en los retrovirus y que posibilita sintetizar ADN a partir de ARN, lo que implica que la información genética también puede "viajar" en otro sentido: ARN $\rightarrow$ Proteína (transcriptasa inversa) $\rightarrow$ ADN.

Si entendemos por dogma a una verdad irrefutable, un principio innegable y establecido para siempre, entonces la propuesta de Crick no clasifica como tal. Por otra parte, a pesar de que este término también tiene asidero en el terreno científico (según la Real Academia Española), ¿no es éste más apropiado para la religión? Las verdades científicas están sujetas a la crítica, a la revisión y a la prueba; los dogmas religiosos, al estar sustentados en la fe, no son susceptibles de ser cuestionados. Como veremos, la segunda situación que he planteado, en la que ciertos eslóganes se vuelven (aparentemente) inamovibles, se enmarca en el dogmatismo, principalmente porque dichos eslóganes beben de (y alimentan a) dos fuentes que para algunos son totalmente compatibles (y hasta indistinguibles): la ciencia y la religión. 
Ya se habrá advertido que he usado como título de este escrito la que quizá es la frase más famosa de la ciencia de lo vivo: "Nada en biología tiene sentido si no es a la luz de la evolución"'. Además, también se habrá hecho evidente que la he puesto entre signos de interogación, y éste no es un detalle menor. A diferencia de mucha gente (en especial con formación en biología), he decidido cuestionar la validez y pertinencia de esta frase, en aras de argumentar por qué debemos prescindir de ella. Éste es el objetivo central del artículo 3 .

La crítica a este eslogan se puede hacer en, al menos, tres ámbitos claramente interconectados. El primero es en el terreno "netamente" biológico, pues, a mi modo de ver, esta frase conlleva una idea reduccionista, en donde se menosprecia el trabajo de muchos biólogos que no están directamente vinculados a los problemas evolutivos. Por supuesto que la historia evolutiva importa en biología, pero no es lo único que importa. Dado que el autor de la frase es Theodosius Dobzhansky (1900-1975), uno de los "arquitectos" de la Síntesis Evolutiva, que la acuñó, en parte, para cimentar el papel omnipotente de la evolución (la cual entendió como un acto de dios), y que carezco de un nombre mejor, la denominaré como el Dogma Central de la Sintesis Evolutiva (en adelante DCSE). Permítaseme explicar brevemente por qué considero que el DCSE nos lleva al reduccionismo y por qué lo denomino como "dogma".

Hay diversas frases que se han propuesto como una manera de complementar el DCSE. Una de ellas es de Francisco Ayala (apud BARAHONA, 2009, p. 5): "Nada en evolución tiene sentido si no es a la luz de la genética". Alguien podría decir (si no lo ha hecho) que "Nada en genética tiene sentido si no es a la luz de la biología molecular". Otra persona podría añadir (si no lo ha hecho): "Nada en biología molecular tiene sentido si no es a la luz de la química", y así sucesivamente. Desde luego que la genética no se reduce a la biología molecular (ni ésta a la química), así como la evolución no lo hace con respecto a la genética, ni la biología entera a la evolución. Espero que esta reflexión introductoria empiece a dejar claro por qué propongo abandonar el DCSE.

Paso ahora a explicar por qué denomino a la frase como "dogma", y esto me lleva a retomar los ámbitos segundo y tercero de mi crítica. Como mostraré adelante, Dobzhansky utilizó el DCSE como título de una conferencia que dio en un congreso de profesores de biología, la que luego se publicó en una revista especializada en la enseñanza de esta ciencia.

\footnotetext{
${ }^{2}$ Esta frase se ha usado indiscriminadamente (principalmente como epígrafe) en muchos escritos (artículos, libros, ensayos, etc.). Ejemplos notables son: como epígrafe (de todo el libro) y como frase final del primer capítulo en Dobzhansky et al. (1993), y como título del $6^{\circ}$ capítulo de Burian (2005). Se podría hacer un rastreo de su uso, por ejemplo en Internet, y muy seguramente ello nos arrojaría resultados impresionantes. Un sondeo en Google, digitando la frase arrojó cerca de ¡4’380.000 resultados! ${ }^{3}$ Griffiths (2009) también cuestiona la pertinencia de esta frase, pero se centra en criticar la idea de evolución como adaptación, y deja de lado los temas en los que me centro. Así pues, este trabajo y el de ese autor pueden verse como complementarios.

${ }^{4}$ Tomo esta frase de la introducción del texto de Barahona (2009, p. 5), quien la usa en su epígrafe. La autora cita, en primer lugar, la frase de Dobzhansky y, a renglón seguido, cita la de Ayala. Desconozco cuál es el origen de esta última (no sé en qué contexto surgió). En este escrito me limito a hacer una "genealogía" de la primera. Por otra parte, es importante decir que recientemente se publicó un artículo con el sugerente título de "¿Nada en evolución tiene sentido si no es a la luz de la genética de poblaciones?” (BROMHAM, 2009). Todo parece indicar que la respuesta de la autora es afirmativa.
} 
Así pues, el DCSE tiene implicaciones en el área de la didáctica de la biología (tercer ámbito), pero no sólo en él. Como también se verá, en ese artículo Dobzhansky defiende una idea de evolución ligada al creacionismo, doctrina de la cual no se apartó nunca. Puesto que este autor hace una mezcla, desde mi punto de vista problemática, entre evolución y creación, entonces la palabra dogma nos cae como anillo al dedo. Por estas razones, el DCSE también tiene implicaciones para la filosofía de la biología (segundo ámbito). Llegados a este punto, es importante que nos adentremos en el origen del DCSE.

\section{1973 y el origen del “dogma central de la síntesis evolutiva”}

Dobzhansky pronunció una conferencia ante la American Association of Biology Teachers a inicios de la década de 1970 (BURIAN, 2005, p. 104), cuyo texto se publicó, usando el mismo título "Nothing in Biology Makes Sense Except in the Light of Evolution" (DOBZHANSKY, 1973), en una de las más prestigiosas revistas sobre enseñanza de la biología en el contexto angloparlante: The American Biology Teacher. De acuerdo con Burian (2005), ese eslogan se usa frecuentemente en dos tipos de controversias: las que versan sobre el estatus de la evolución en la biología y las que aluden a los debates culturales entre evolución y religión ${ }^{5}$.

En esa sección lo que haré básicamente es una síntesis de los puntos que, a mi parecer, son los más controversiales del "artículo fundador" del DCSE. Como veremos, Dobzhansky (1973) creyó que con su escrito estaba arrojando luz sobre el "presunto" conflicto evolución vs creación, pero en verdad nos legó un panorama bastante oscuro sobre este asunto. En ese sentido, vale la pena recordar que la sociedad estadounidense ha sido la que mayor resistencia (al menos en el mundo occidental) le ha puesto a la teoría evolutiva, situación que ha llegado incluso al límite de interponer demandas para establecer leyes que eviten que ésta se enseñe en la escuela, o que se haga hombro a hombro con lo que erróneamente se ha denominado como el creacionismo científico. Uno podría pensar que, en este contexto, Dobzhansky (1973) hubiese abogado por aunar esfuerzos para que se reconociera que el creacionismo, al no ser científico, no puede estar a la par de, o que es inconmensurable con, la teoría evolutiva. No obstante, es sorprendente que él se haya situado en ambas orillas del río ${ }^{6}$.

\footnotetext{
${ }^{5}$ Llama la atención que Burian (2005) no diga mayor cosa sobre la postura problemática de Dobzhansky en lo que respecta a la segunda controversia, ya que alude a su artículo de 1973, pero no parece interesarse en las desconcertantes frases que dicho autor plantea allí. Como se mostrará adelante, Dobzhansky entiende la evolución como un acto de Dios, y eso es controversial. A mi modo de ver, uno no puede sostener que los organismos que pueblan y han poblado este planeta (incluidos nosotros) tienen su origen a la vez en un plan divino y en un proceso natural. Las dos opciones son mutuamente excluyentes, como lo sabía muy bien Darwin, pero éste no era el caso para Dobzhansky. Desarrollaré este último punto en la parte final de este escrito.

${ }^{6}$ Sin duda, un científico puede ser también una persona religiosa; eso no es problemático. Lo que es controversial es que un científico explique el mundo natural con base en sus creencias religiosas, lo cual parece ser el caso en Dobzhansky.
} 
Para aprender el dogma creacionista no es necesario ir a la escuela, pues este adoctrinamiento empieza en casa. Nada semejante ocurre (por lo menos para el grueso de la población) con los conocimientos científicos.

Sin más preámbulos, entremos al análisis del artículo en cuestión (DOBZHANSKY, 1973) ${ }^{7}$. El documento está dividido en 6 partes: 1) Introducción, 2) Diversidad de los seres vivos, 3) Unidad de la vida, 4) Anatomía y embriología comparadas, 5) La radiación adaptativa: moscas de Hawái y 6) La fuerza y la aceptación de la teoría evolutiva.

En el apartado introductorio, Dobzhansky se ocupa de criticar lo que el Jeque Abb el Aziz le había dicho al rey de Arabia Saudita (en 1966), con respecto a que el Corán, los profetas musulmanes y los científicos del islam habían enseñado que el sol gira en su órbita, alrededor de la Tierra, por lo que habría que suprimir la herejía copernicana (p. 125). Dobzhansky arguye que el Jeque no conoce, o no quiere reconocer, una serie de hechos que demuestran que el heliocentrismo es cierto $^{8}$. También alude al hecho de que la Biblia y el Corán no contradicen a Copérnico, así como éste no lo hace con aquéllos: "Es ridículo confundir la Biblia y el Corán como manuales de ciencia natural. Ellos tratan de materias aún más importantes: el significado del hombre y sus relaciones con Dios [...] La Tierra no es el centro geométrico del universo, sino su centro espiritual'9 (p. 125, énfasis nuestros).

En la segunda parte, Dobzhansky se refiere a las diversas pruebas que dan cuenta de la desbordante diversidad de la vida, tales como evidencias taxonómicas, morfológicas y moleculares. Una forma de asumir esa diversidad es con relación a los hábitats que las especies pueden ocupar: "Algunos organismos viven en gran variedad de ambientes. En este respecto, el hombre está en la cumbre de la escala" (p. 126, énfasis nuestro).

Renglones después, Dobzhansky afirma que no hay nada consciente o intencional en la selección natural; las especies no deciden evolucionar: "Solamente el ser humano toma esas decisiones conscientes. Ésta es la razón de por qué el Homo sapiens es el ápice de la evolución" (p. 127, énfasis nuestro). Más adelante sostiene que "Los anti-evolucionistas fallan en comprender cómo actúa la selección natural. Ellos se imaginan que todas las especies existentes fueron generadas por un mandato sobrenatural pocos miles de años atrás, más o menos como las encontramos hoy" (p. 127). Esta frase puede dar la idea de que Dobzhansky no es creacionista, pero sí lo es. Aquí está dirigiendo sus dardos en contra de los "anti-evolucionistas" (que en su lenguaje no es sinónimo de creacionistas), es decir a quienes por razones religiosas no asumen que la evolución es un hecho. Para empezar a despejar las dudas acerca su sus ideas creacionistas, leamos lo que dice, a manera de conclusión, en el segundo apartado:

\footnotetext{
${ }^{7}$ En lo que queda de esta sección, cuando cite textualmente o parafrasee pasajes de este artículo, solamente me referiré a la página en la que el autor expresa la idea aludida.

${ }^{8}$ Llama la atención que Dobzhansky, para criticar el fundamentalismo religioso, tome un ejemplo del mundo musulmán, pero no diga nada de los fundamentalistas cristianos que propusieron, en varios estados y en diferentes momentos, prohibir la enseñanza de la evolución en la escuela y suprimirla de los libros de texto de los Estados Unidos (su patria adoptiva).

${ }^{9}$ Ésta y todas las demás citas tomadas de un idioma diferente al español han sido traducidas por el autor de este artículo.
} 
La diversidad orgánica llega a ser, sin embargo, razonable y comprensible si el Creador ha creado (sic) el mundo viviente no por capricho, sino a través de la evolución propulsada por selección natural. Es erróneo sostener que la creación y la evolución son alternativas mutuamente excluyentes. Yo soy un creacionista $y^{10}$ un evolucionista. La Evolución es el método de creación de Dios o de la Naturaleza. La creación no es un evento que ocurrió en el año 4.004 A.C.; éste es un proceso que empezó hace aproximadamente 10.000 millones ${ }^{11}$ de años y aún está en marcha. (p. 127, énfasis nuestros)

Después de estas contundentes palabras, Dobzhansky se adentra, en la tercera sección, en el tema de la unidad de la vida. Aquí trae a colación evidencias moleculares como la universalidad del código genético. Una vez que plantea la unicidad molecular de la diversidad viviente, nos dice lo siguiente:

Pero, ¿qué tal si la evolución no hubiera ocurrido, y cada una de los millones de especies hayan sido creadas de manera independiente? A pesar de lo ofensiva que la noción pueda ser para el sentimiento religioso y para la razón, los anti-evolucionistas pueden acusar [...] de engañoso al Creador. Ellos deben insistir en que Él deliberadamente dispuso las cosas exactamente como si su método de creación fuera la evolución, intencionalmente para confundir a los sinceros buscadores de la verdad. (p. 127) ${ }^{12}$

Dobzhansky inicia el cuarto apartado con estas palabras:

Los universales bioquímicos son los más impresionantes y los más recientemente descubiertos, pero ciertamente no son los únicos vestigios de la creación por medio de la evolución. La anatomía y la embriología comparadas ponen de manifiesto los orígenes evolutivos de los actuales habitantes del mundo. (p. 128, énfasis nuestro)

Luego se refiere a las innumerables homologías presentes en diferentes organismos y a la ley biogenética de Haeckel, en especial a su más famoso ejemplo: la presencia de hendiduras branquiales en los primeros estadios de los embriones de mamíferos, como el humano:

${ }^{10}$ Este énfasis es del original.

${ }^{11}$ En el original: 10 billion.

${ }^{12}$ Sin duda, esta afirmación es ambigua si leemos la cita previa. 
Por supuesto, en ningún estadio de su desarrollo el embrión humano es un pez, ni esto implica que tenga branquias funcionales. Pero, ¿por qué el embrión humano debería tener hendiduras branquiales inconfundibles a menos que sus ancestros remotos respiraran con la ayuda de agallas? (p. 128)

La quinta sección versa sobre diferentes datos acerca de la diversificación de las especies. Dobzhansky habla particularmente de las cerca de 500 especies de Drosophila que habitan el archipiélago hawaiano. Ahí sostiene que

Otras islas oceánicas del Pacífico, diferentes a las de Hawái, no son conspicuamente ricas en especies endémicas de drosófila. La explicación más probable de este hecho es que esas otras islas fueron colonizadas por drosófilas después de que la mayoría de nichos ecológicos estuvieron ocupados (sic) a causa de los primeros arribos. Ésta seguramente es una hipótesis, pero una razonable. Los anti-evolucionistas quizá podrían sugerir una hipótesis alternativa: en un momento de distracción, el Creador continuó fabricando más y más especies de drosófila para Hawái, hasta que hubo un extravagante exceso de ellas en este archipiélago. Les dejo a ustedes la decisión sobre qué hipótesis tiene sentido. (p. 129)

La sexta y última parte del artículo es, desde mi punto de vista, la más problemática, por lo que de ella tomaré buena parte del material para la crítica posterior. Para iniciar, el pasaje que cito a continuación es tal vez el que mejor evidencia la perspectiva reduccionista del DCSE que mencioné en la introducción:

Vista a la luz de la evolución, la biología es, quizá, intelectualmente la ciencia más satisfactoria e inspiradora. Sin esa luz, la biología llega a ser un montón de hechos dispersos -algunos de los cuales son interesantes y curiosos, pero no elaboran una imagen significativa como un todo. (p. 129)

Posteriormente, añade que en la biología no se puede aspirar a la completitud y que en esta ciencia hay muchas controversias, las cuales son aprovechadas por los anti-evolucionistas al

[...] malinterpretar, o pretender confundir, esos desacuerdos como indicaciones dudosas acerca de la doctrina entera de la evolución. Su pasatiempo favorito es articular citas, cuidadosa y a veces expertamente tomadas fuera de contexto, para mostrar que nada está realmente establecido o acordado entre los evolucionistas. Algunos de mis colegas y yo mismo nos hemos entretenido y asombrado al vernos citados de un modo que nos muestra como siendo realmente anti-evolucionistas bajo la piel [...] La evolución como un proceso [...] sólo puede ser 
puesto en duda por aquéllos que ignoran la evidencia, o que se resisten a ella, debido a bloqueos emocionales o a simple intolerancia. (p. 129)

Como se hará evidente a partir de las citaciones que siguen, y de las que traeré a colación principalmente en los párrafos finales de este artículo, Dobzhansky deja poco lugar a las dudas acerca de que su visión de la evolución lo aleja mucho de la propuesta original de Darwin. ¿Esto lo convierte en un anti-evolucionista? Creo que sí. Como antesala de la justificación de esta respuesta, leamos lo que Dobzhansky plantea en las últimas líneas de su escrito:

¿La doctrina evolutiva entra en conflicto con la fe religiosa? No [...] Uno de los grandes pensadores de nuestro tiempo, Pierre Teilhard de Chardin ${ }^{13}$, escribió lo siguiente: «¿Es la evolución una teoría, un sistema o una hipótesis? Es mucho más -es un postulado general al cual todas las teorías, todas las hipótesis, todos los sistemas deben someterse en lo sucesivo, y al que deben satisfacer para que sean concebibles y verdaderos. La evolución es una luz que ilumina todos los hechos, es una trayectoria a la que todas las líneas de pensamiento deben seguiresto es la evolución» Por supuesto, algunos científicos, como también algunos filósofos y teólogos, están en desacuerdo con ciertas partes de las enseñanzas de Teilhard [...] Pero no hay ninguna duda de que [él] fue un auténtico y profundo hombre religioso, y que la cristiandad fue la piedra angular de su visión del mundo [...] Teilhard fue un creacionista, pero uno que comprendió que la Creación es realizada en este mundo por medio de la evolución. (p. 129)

Las críticas a este tipo de afirmaciones serán abordadas en la parte final del artículo. Por ahora quisiera cerrar esta sección haciendo un comentario sobre el contexto en el que fue escrito el trabajo de Dobzhansky. Como ya se dijo, éste se publicó en una revista sobre enseñanza de la biología, por lo que cabría esperar que la mayoría de sus lectores sean profesores de esta ciencia. Sin embargo, Dobzhansky no dice nada acerca de cómo sus reflexiones podrían ayudar a mejorar la educación en biología. En ese sentido, vale la pena citar la única alusión que hace al respecto: "La educación no ha de ser usada para promover el oscurantismo" (p. 125). Pasemos, entonces, a exponer las implicaciones que tienen los planteamientos de este autor.

${ }^{13}$ Fue un sacerdote jesuita y paleontólogo francés (1881-1955). Como se pondrá de manifiesto posteriormente, él fue la persona a quien más admiró Dobzhansky. 


\section{Implicaciones del "dogma central de la síntesis evolutiva” para la Biología, su Filosofía y su Enseñanza}

Para empezar, es necesario hacer una distinción: una cosa es ver las implicaciones de lo que dijo Dobzhansky en su artículo de 1973 (y en otros documentos), y otra es analizar las consecuencias de la forma irreflexiva en que se ha usado el título del mismo (el DCSE). En este trabajo me centro en la primera opción. Sin duda, se podría sostener que dado que él fue uno de los más férreos promotores de la Síntesis Evolutiva, su frase célebre no hace más que reflejar la "esencia" de esa corriente de pensamiento en biología. Como hemos visto, el objetivo central de Dobzhansky (1973) no es otro sino demostrar que evolucionismo y creacionismo son "doctrinas" totalmente compatibles y que, además, la evolución no es más que el método que dios ha usado para crear la naturaleza viviente. No creo que los otros "arquitectos" de la Síntesis Evolutiva hubiesen compartido la adscripción creacionista de Dobzhansky, aunque sí creo que se identificaron con el hecho de que lo realmente importante en biología es la teoría de la evolución. Por supuesto que ambas ideas son cuestionables.

También es preciso hacer una aclaración: el trabajo científico de Dobzhansky no está en cuestión aquí1 ${ }^{14}$. En ese sentido, es necesario recordar que él ayudó a sintetizar dos tradiciones que estaban totalmente distanciadas: la experimentalista de la genética y la naturalista (más cercana al darwinismo) ${ }^{15}$, lo que se evidencia en su insistencia en valorar la importancia del método experimental en la evolución y, en general, en estimular la coexistencia de ésas y otras tradiciones: "La genética es la primera ciencia biológica que se coloca en la posición en la que la física ha estado por muchos años. Podemos hablar justificadamente acerca de algo como genética teórica-matemática y de genética experimental, al igual que en la física" (DOBZHANSKY, 1962, apud ARAÚJO, 1998, p. 48).

El quehacer científico de Dobzhansky, por otra parte, pone en cuestión la propuesta de Mayr (2006) acerca de que hay dos campos separados en la biología: la funcional (o más en general la experimental, que se ocupa principalmente de las causas próximas) y la evolutiva (es decir, histórica que da cuenta de las causas remotas). Claro que Mayr (2006) propuso esta dupla como un intento por demostrar que la biología no es un todo unificado, pero la historia de la biología nos ha enseñado no sólo cómo estos campos se entrelazan complejamente, sino que existen otras formas de hacer biología (como la perspectiva matemática de la genética de poblaciones, por ejemplo). En este punto es interesante señalar que Mayr (2006, p. 113) refiriéndose a la famosa frase de Dobzhansky (el DCSE), dijo que ésta es seguramente cierta, pero

\footnotetext{
${ }^{14}$ Como tampoco lo están sus invaluables aportes en la institucionalización de la genética en varios países, entre ellos dos latinoamericanos: Brasil (ARAÚJO, 1998) y México (BARAHONA; AYALA, 2005).

${ }^{15}$ Un análisis detallado del trabajo de Dobzhansky en esos dos frentes que parecían irreconciliables se encuentra en el libro de Kohler (1994), particularmente el capítulo 8: "From laboratory to field: evolutionary genetics" (p. 250-293). De especial interés es el cambio de material y de sitio de trabajo, pues Dobzhansky pasó de estudiar la Drosophila melanogaster (un organismo estándar, cuyos mutantes no habitan sino en algunos laboratorios) a hacer investigaciones con Drosophila pseudooscura (un organismo que se adapta mal al laboratorio y que, por lo tanto, hay que estudiar fundamentalmente en el campo).
} 
solamente para la biología no funcional (histórica), lo cual sería decir algo como esto: nada en la biología no funcional (evolutiva) tiene sentido si no es a la luz de la evolución, y esto equivale a sostener que la evolución es imprescindible para la biología evolutiva.

A pesar de mi burla a Mayr, debo admitir que lo que él dice nos lleva a algo importante: reconocer que hay otros dominios de la biología en donde la teoría evolutiva no es indispensable. No obstante, otros autores han caído en la trampa de intentar justificar a medias el DCSE: “[...] Podemos, y deberíamos, tomar el eslogan de Dobzhansky en el sentido de que la historia importa. Nada en biología tiene ningún sentido excepto en el contexto de su lugar en la filogenia, su contexto en el gran árbol de la vida" (STERELNY; GRIFFITHS, 1999, p. 379, énfasis de los autores).

Desde luego que en biología la historia importa, iy muchísimo! ${ }^{16}$. Me atrevo a decir que su carácter histórico es quizá el rasgo más distintivo de la biología en relación con las otras ciencias de la naturaleza. Se podría objetar que lo mismo ocurre con la geología, pero la contingencia de la historia evolutiva que ha dado origen a diferentes linajes, a muchas extinciones y a diversas adaptaciones no tiene parangón en otras ciencias. No hay nada como "descendencia con modificación" (para usar un término de Darwin ${ }^{17}$ ) en las moléculas químicas o en los estratos geológicos. No hay selección natural que permita la "supervivencia" de determinadas poblaciones de rocas ígneas, o extinción (en el sentido biológico) de placas tectónicas. De acuerdo, la historia importa, pero sin hallazgos en diferentes campos como la geología, la anatomía y embriología comparadas, la horticultura, la ganadería (y en general la crianza de animales), la economía, la demografía (recuérdese la influencia de Malthus en Darwin y Wallace), etc., no tendríamos una teoría evolutiva (CASTRO, 2009). Más específicamente, sin otras ramas de la biología, la evolución sería incomprensible. Así pues, no hay una piedra angular en la biología. He aquí una respuesta a la pregunta que se plantea en el título de este artículo.

Lo anterior nos permite hacer la conexión con algunas implicaciones que en la filosofía de la biología tiene (parte) del trabajo de Dobzhansky. En primer lugar, vale la pena señalar que el surgimiento de la teoría sintética de la evolución, en la década de 1930, tuvo una influencia significativa del empirismo lógico, ya que desde ambas perspectivas se intentó unificar a la ciencia (en lo que respecta a las teorías, al método y al lenguaje) (ARAÚJO, 1998, p. 48). Como vimos, el DCSE expresa claramente el presupuesto de que toda la biología debe sustentarse en la teoría de la evolución. Pero también vimos que éste no tiene por qué ser el caso.

Por otro lado, debemos recordar que Dobzhansky prestó mucha atención a la filosofía de la biología, y allí también hizo contribuciones importantes. Este hecho se evidencia en la siguiente cita: "Mi interés en la genética vino de mi interés en la evolución - mi interés en evolución, puedo decirlo, fue filosófico, éste llegó primero; mi interés en genética procede de aquél. Por lo tanto, no dudo que desde el principio ése era el tema en el que quería entrar" (DOBZHANSKY, 1962 apud ARAÚJO, 1998, p. 52) ${ }^{18}$.

\footnotetext{
${ }^{16}$ Como lo afirma Gould (1986, p. 60), Darwin fue sobre todo un metodólogo histórico, pues nos enseñó a emplear el método de la historia como otra forma de hacer ciencia (diferente a la centrada en el experimento y la observación).

${ }^{17}$ Véase Darwin (2009), en especial el capítulo VI (p. 169-202).

${ }^{18}$ Además, según Abrantes (2011, p. 11), Dobzhansky (junto con Ayala) coordinó uno de los primeros libros sobre filosofía de la biología en el contexto anglosajón.
} 
Sin embargo, en algunos lugares en que Dobzhansky se adentra en reflexiones filosóficas de la biología, deja al descubierto su pensamiento progresivo, teísta y direccional con respecto al proceso evolutivo. Ya vimos que esto es lo que manifiesta en su artículo de 1973, pero, para allegar más elementos de análisis, traeré a colación otras afirmaciones de este autor, tomadas de diversas fuentes, que versan sobre sus ideas de progreso y direccionalidad:

En general, cada especie es superior a todas las demás en su propio nicho adaptativo, porque si otra especie fuera superior, ésta expulsaría a la primera. Pero es ridículo concluir con base en esto que no ha habido progreso en la evolución, y que el hombre no es un organismo más perfecto que un gusano o una ameba. (DOBZHANSKY, 1955 apud ARAÚJO, 2000, p. 26)

Desde esta perspectiva se podría argumentar que, en su momento, los dinosaurios (¿pero cuál de todas las especies que hubo?) eran los organismos más "perfectos" que existían en la Tierra. ¿Se extinguieron a causa de que otra especie "superior" los expulsó del Edén de su "nicho adaptativo"? No. Sin duda esto se debió, sobre todo, a un hecho contingente no biológico: el impacto de un gran meteoro contra nuestro planeta. El famoso "experimento mental" de Gould (1989), de rebobinar la cinta de la película evolutiva, es muy ilustrativo aquí. Si regresáramos la cinta y la pusiéramos a andar nuevamente, ¿deberíamos esperar que todo ocurriera igual, en la misma secuencia, y que de todos modos hoy estaríamos en la cúspide de la evolución contando la historia de los dinosaurios? Leamos más sobre el progreso:

El hombre, el pináculo de la evolución ${ }^{19}$. Una de las maneras más sencillas de satisfacer nuestro ego es considerarnos superiores a otros. Por esta razón, la opinión que el hombre se encuentra en el escalón más alto de la escalera del progreso debe ser escudriñada con cuidado. Sucede, sin embargo, que por medio de todos los criterios sensibles de progreso el hombre es superior a las otras criaturas [...] la evidencia concluyente sobre la posición superior del hombre es que en él, y solamente en él, ha evolucionado el genotipo que lo faculta para desarrollar y mantener una cultura. La cúspide biológica del hombre es una eminencia solitaria; ninguna otra especie puede aspirar a disputársela. (DOBZHANSKY, 1955 apud ARAÚJO, 2000, p. 27)

\footnotetext{
${ }^{19}$ Esta idea lo acompañaría hasta los últimos días de su vida. En el capítulo de su autoría "Evolución del género humano", en Dobzhansky et al. (1993, p. 439) podemos leer: "El hombre es, sin lugar a dudas, el producto más competente y dominante del proceso evolutivo. Esta afirmación no quiere decir que resulte impensable una posible decadencia y extinción de la especie humana: muchas especies con un éxito enorme han acabado extinguiéndose. Pero no hay ninguna especie, excepto la humana, que haya presentado una influencia directiva sobre su propia evolución. Por lo tanto, si la humanidad se extinguiese, se trataría del primer caso de suicidio evolutivo de una especie biológica." Debo el hallazgo de esta frase al texto de Oliveira (1998, p. 59).
} 
Podemos citar nuevamente a Gould para hacer frente a este tipo de afirmaciones. En su artículo de 1986 (p. 69) dice que "la evolución es un árbol, no una escalera". En particular, Gould se refiere a la evolución como un proceso contingente y ramificado, y cuando alude al origen del ser humano dice que éste fue reciente y discreto, presumiblemente a partir de una población local y aislada que fue coronada con excesivos éxitos posteriores. Por su parte, cuando habla de las homologías entre especies, Gould dice que ellas se deben a las contingencias de la historia y no a profundas inmanencias del espíritu.

En cuanto a la cuestión de la direccionalidad en la evolución, hay que decir que en 1968 Dobzhansky (apud ARAÚJO, 2000) escribió un artículo en el que expuso la manera en que Teilhard de Chardin entendía este tema. Al año siguiente, aquél asumió la presidencia de la American Teilhard de Chardin Association, y a partir de estos acontecimientos, según Araújo (2000, p. 30), Dobzhansky empezó a escribir usando una redacción en la que no ocultaba su condición de persona extremadamente religiosa.

Llegados a este punto, voy a ocuparme de algunas implicaciones didácticas de las ideas aquí expuestas. No está de más insistir en que era de esperarse que Dobzhansky mencionara, en su texto de 1973, cómo la frase "Nada en biología tiene sentido si no es a la luz de la evolución" permite a los maestros de biología cualificar su trabajo, toda vez que dicho texto se publicó en una revista dirigida a (y construida por) ese gremio. Como vimos, nada de eso se puede extraer del contenido del artículo. Quedaría por indagar, y eso no es poco trabajo, cómo han recibido (en ese entonces y ahora) los profesores de biología las enseñanzas de Dobzhansky. En lo que sigue me referiré a cómo los planteamientos del científico norteamericano (de origen ucraniano $)^{20}$ inciden en la enseñanza de la biología.

Oliveira (1998, p. 65) analiza las ideas sobre progreso evolutivo en Dobzhansky (y en Julian Huxley), algunas de las cuales ya citamos. Luego, esta autora procede a mostrar ciertos pasajes de entrevistas hechas a estudiantes de licenciatura en ciencias biológicas de la Universidade Federal do Rio Grande do Sul, y allí se evidencia que ellos conciben, en gran medida, que la evolución es un proceso progresivo, de mejora y con una direccionalidad (definida) ${ }^{21}$. Oliveira (1998) sugiere que las ideas de los estudiantes universitarios acerca de que la evolución es progresiva tienen sus orígenes en diversos autores de la Síntesis Evolutiva (incluyendo a Dobzhansky), quienes han permeado las concepciones de los biólogos evolutivos actuales y éstos, a su vez, han incidido en los maestros de biología y en sus estudiantes. Este punto se puede sustentar con lo que plantea Ayala en el capítulo "Aspectos filosóficos", en Dobzhansky et al. (1993, p. 505-507):

¿Qué queremos decir con «progreso evolutivo»? ¿En qué sentido podemos decir, si podemos hacerlo, que la evolución es progresiva? Puede aclararse el término «progreso» comparándolo con otros términos relacionados utilizados en los argumentos biológicos. Estos otros tér-

\footnotetext{
${ }^{20}$ Es un lugar común decir que Dobzhansky era ruso, lo cual no es cierto, pues nació en la ciudad de Nemirov, Ucrania, y se formó como biólogo en la Universidad de Kiev.

${ }^{21}$ En menor medida la entienden como un acto de Dios. 
minos son «cambio», «evolución» y «dirección» [...] El progreso puede, pues, ser definido como el cambio sistemático de una característica que se presenta en todos los miembros de una secuencia de tal modo que los miembros posteriores de la secuencia muestran una mejora de dicha característica. El progreso puede ser definido de forma más sencilla como un cambio direccional hacia algo mejor. El antónimo de progreso es «regresión» o cambio direccional hacia lo peor. Los dos elementos de la definición, en realidad el cambio direccional y la mejora respecto a algún patrón resultan ambos necesarios y suficientes para que se produzca el progreso. (énfasis del autor)

Esta cita tiene problemas, ya que ¿bajo qué criterios se puede decir que una especie es mejor que otra? Además, ¿por qué Ayala alude al antónimo "regresión"? Es obvio que no tiene sentido hablar de involución (si es que algo así existe). Por ejemplo, parásitos como la tenia, si son comparados con otros platelmintos, pero de vida libre, podrían verse como "regresivos", porque han "perdido" el sistema digestivo y las estructuras que les permitirían percibir la luz. Pero si lo vemos desde otra perspectiva, han ganado en adaptarse a un medio que para otros organismos sería inhabitable. ¿Son las tenias regresivas o han involucionado? Por supuesto que no. Sin embargo, el punto a discutir acá es cómo en los libros de texto para la enseñanza de la evolución (el de Dobzhansky et al..$^{22}$ es un clásico) circulan este tipo de ideas que servirán como base en la formación de las nuevas generaciones (en este caso de biólogos y profesores de biología). Sin embargo, hay que aclarar que el problema del progreso en evolución es un tema aún en debate en la filosofía y en la historia de la biología. El mismo Darwin reconoció lo problemático del asunto, aunque no es tan fácil discernir cuál era su posición al respecto ${ }^{23}$

Pero no podemos perder de vista que

El impacto [del texto El origen de las especies] se debió, en gran medida, a la percepción de que esta teoría cambia la posición del ser humano, haciendo de él un producto de la evolución emparentado con los restantes animales, con lo cual deja de ser una entidad «diferente» y superior. (JIMÉNEZ, 2003, p. 125, énfasis de la autora)

Hay que tener presente que para Dobzhansky (1973) la evolución va en dirección de un punto culminante: el ser humano y, siguiendo a Jiménez (2003), la pregunta por nuestro origen, y el de las demás especies, es una que suele estar ausente de los libros de texto y en algunos planes de estudio.

${ }^{22}$ Uno de los coautores de ese texto es, precisamente, Ayala.

${ }^{23}$ Sobre estos temas véanse los escritos de la segunda parte del libro compilado por Martínez y Barahona (1998). 
No está de más decir que el aprendizaje de la evolución se ve obstaculizado por las nociones de creación, direccionalidad, progreso, perfección, etc., ya que éstas son contrarias a la comprensión de la historia evolutiva como un proceso natural y contingente:

[Las] concepciones teleológicas o finalistas de los alumnos muestran la evolución como un camino con un objetivo prefijado. Así, los organismos evolucionan inevitablemente porque progresan. La evolución de una especie sirve para llegar hasta un estado más perfeccionado o más equilibrado con la naturaleza. (GUTIÉRREZ, 2009, p. 110)

En ese sentido, es factible ver algunas implicaciones de reconocer la importancia de la perspectiva histórica en la enseñanza de la biología:

La ciencia histórica es aún ampliamente mal comprendida, subestimada o denigrada. La mayoría de los jóvenes primero se halla ante la ciencia, en su educación formal, aprendiendo acerca del poderoso modo de razonamiento llamado 'el método científico'. Más allá de unos pocos tópicos acerca de la objetividad y la disposición a cambiar su mentalidad, los estudiantes aprenden un estrecho estereotipo sobre la observación, la simplificación de probar aparte variables controladas, el experimento crucial y la predicción con repetición como un test [...] Así, cuando los estudiantes luego se enfrentan a la historia, donde los eventos complejos ocurren tan solo una vez [...] ellos solamente pueden concluir que tal asunto debe ser menos que ciencia. Y cuando los estudiantes se aproximan a la diversidad taxonómica, o a la historia filogenética, o a la biogeografía - donde el experimento y la repetición tienen aplicación limitada a los sistemas en su totalidad - ellos sólo pueden concluir que se hallan ante algo indigno de la ciencia, frente a algo meramente 'descriptivo'. (GOULD, 1986, p. 64, énfasis del autor)

Reitero que la frase de Dobzhansky (1973) puede ser entendida como un reclamo para que la historia ocupe el lugar que se merece, pero hemos visto que se ha asumido como un dogma, el cual sostiene que, en biología, la evolución (como acto de dios) es lo único que importa. Deberíamos entender el asunto como lo plantea Gould (1986): que el método histórico también es una forma de hacer ciencia. En este sentido, en el contexto de la enseñanza de la biología deben cobrar relevancia estrategias didácticas como la elaboración de narraciones históricas, sin que ello implique demeritar el desarrollo de otras actividades como la experimentación; la construcción de modelos (modelización); la observación, por ejemplo a través del microscopio; y el trabajo de campo. Todas estas estrategias son importantes en los procesos de enseñanza-aprendizaje de la biología, cada una de las cuales cumplirá un rol más o menos central, dependiendo de la temática de la que se trate (CASTRO; VALBUENA, 2007). "A esto puede agregarse que para enseñar biología evolutiva es necesario enseñar biología funcional, ya que la evolución biológica no tiene lugar en el vacío" (RUIZ et al., 2012, p. 85). 
Ésta es otra forma de asumir que no hay un paradigma (en el sentido de ejemplar) que deba guiar los procesos de elaboración del conocimiento biológico ni en la comunidad científica ni en la comunidad escolar. No obstante, como nuestra discusión gira en torno al papel de la evolución y su relevancia en la educación científica, es preciso que volvamos a ello.

Recientemente, Bizzo y El-Hani (2009, p. 112) se han preguntado ¿Por qué deberían los estudiantes de escuela secundaria aprender evolución? A lo que han respondido con 7 líneas de razonamiento, dentro de las cuales destaco las siguientes: discutir las consecuencias éticas del hecho de estar genealógicamente relacionados con los demás organismos, y evidenciar los vínculos históricos entre el surgimiento de la biología y la propuesta de la teoría evolutiva. Sin embargo, llama la atención que estos autores no digan nada acerca de que la evolución nos ayuda a cuestionar el accionar de supuestas fuerzas sobrenaturales en el origen y en el devenir de lo viviente. Si somos el "producto" de un proceso natural y no de un diseño divino (y mucho menos nos hallamos en la cúspide de la creación), ello nos conmina a asumir otra actitud frente a nuestra existencia y la de los demás organismos, lo cual tiene implicaciones de índole ética, por ejemplo. El creacionismo se sustenta en dogmas, el evolucionismo no. Por eso, vale la pena que digamos más al respecto.

Como lo señalan Folguera y Galli (2012), hay un amplio consenso entre los profesores de biología con respecto a la importancia y relevancia de que se enseñen los modelos de la biología evolutiva, pero es igualmente reconocido que los logros alcanzados en este campo están muy lejos de ser los deseables. Uno de los factores que dificultan el aprendizaje de esta temática, según estos autores, es el que atañe a las creencias religiosas de los estudiantes. En ese sentido, Oliveira, Pagan y Bizzo (2012) reportan que en una muestra significativa de estudiantes brasileros, tanto de secundaria como universitarios (que buscan obtener un diploma en biología), un número significativo mostró tener ideas contrarias a la evolución debido a sus creencias religiosas:

Los datos encontrados indican que conocimientos científicos como la teoría evolutiva, pueden sufrir algunas influencias de la premisa creacionista, ya sea por la relectura de los procesos biológicos, integrando la planificación de Dios a la teoría de la evolución, o por el rechazo al conocimiento científico, optando por explicar los fenómenos naturales a partir de sus ideas teístas y de la interpretación literal de la Biblia. (SEPÚLVEDA; EL-HANI, 2004 apud OLIVEIRA; PAGAN; BIZZO, 2012, p. 54)

En suma, el estudio de Oliveira, Pagan y Bizzo (2012) revela que los estudiantes encuestados que están más comprometidos con actividades religiosas son lo que presentan una mayor tendencia a rechazar la enseñanza de la evolución, lo cual es coherente con lo reportado por Ruiz et al. (2012, p. 82), con respecto a una encuesta nacional publicada en México en 2010: "83.6\% de los encuestados confían más en la fe que en la ciencia” y, puntualizan estos autores, "El estudio de la evolución biológica cuestiona el pensamiento determinista porque en los procesos evolutivos también interviene el azar. En tanto no se tenga pensamiento evolutivo, hay un gran margen para asumir el mundo y los fenómenos biológicos como estáticos y mágicos” (p. 82-83). Es posible ampliar la evidencia al respecto: 
Algunas investigaciones muestran la influencia que ejerce, por ejemplo, el cristianismo sobre las explicaciones de los estudiantes a la hora de aprender la teoría evolutiva. Así, existen interpretaciones literales de la Biblia en las que se considera la extinción de organismos como una consecuencia de castigos divinos (¿podríamos pensar entonces que el surgimiento de nuevas especies se corresponde con premios divinos?) y la salvación por decisión divina para los grupos que viven actualmente. Estas posturas aparecen a menudo en trabajos de investigación educativa en Estados Unidos, donde las influencias del creacionismo son importantes en varios estados. (GUTIÉRREZ, 2009, p. 106107)

Aunque no podemos atribuir solamente a Dobzhansky la mezcla de creacionismo/ evolucionismo que es común en muchos estudiantes (y ciudadanos en general) cuando se enfrentan a la enseñanza de la teoría evolutiva, sí podemos preguntar que si esto ocurría en ese autor, ¿qué podemos esperar de estudiantes sin una formación científica tan profunda como la de él? Pero el asunto es más complejo, pues algunos profesores de biología también defienden ese tipo de postulados, por ejemplo en lo que respecta a las nociones de progreso y finalidad en la evolución. Un docente entrevistado por Gutiérrez (2009, p. 146) dice lo siguiente:

Cuando enseñamos el tema de diversidad enseñamos que hay progreso, que se va desde procariotas hasta el hombre, es obvio que estamos mostrando un progreso en cuanto a la complejidad. Los dibujos lineales sobre el proceso evolutivo tratan de mostrar el camino que va de lo más simple a lo más complejo. Que ha habido un desarrollo progresivo [...] [los alumnos] Ven una finalidad en el proceso evolutivo, creo que le ven una finalidad, que es ser cada vez mejores.

Sin embargo, este tipo de presupuestos no sólo se halla en maestros y estudiantes, sino que los libros de texto también contribuyen a afianzarlos. Refiriéndose a un análisis de libros escolares en Argentina, Gutiérrez (2009, p. 120) comenta que:

Entre los resultados encontramos que, de los catorce libros analizados, diez presentan la temática evolutiva en el final del libro [...] Es decir que los textos están aún muy lejos de poder dar «sentido» a la biología y arrojar «luz» en la mayoría de los temas, según enunciaba Theodosius Dobzhansky. (énfasis del autor)

O todo lo contrario; los textos ayudan bastante a vehiculizar las ideas de dicho autor. En uno de los libros examinados por Gutiérrez (2009, p. 121) se presenta esta declaración: "[...] la teoría evolutiva es una imagen dinámica que resulta totalmente coherente con los principios de la teología cristiana" (énfasis del autor). ¿Qué clase de "alfabetización científica" están propiciando estos materiales educativos? 
De acuerdo con Ayala (2013, p. 232), estar científicamente alfabetizado implica que en la escuela se enseñe la teoría de la evolución y no que los humanos fuimos creados hace unos cuantos milenios. En ese sentido, hace un llamado para que la enseñanza de la evolución no sea reemplazada por lo que ahora se denomina el "diseño inteligente". No obstante, ello es contradictorio con lo que sostiene más adelante:

Es necesario que los estudiantes, así como el público en general, conozcan acerca de la evolución biológica. La evolución es el principio central que organiza la biología moderna. Theodosius Dobzhansky afirmó de manera célebre que «nada en biología tiene sentido si no es a la luz de la evolución». (AYALA, 2013, p. 236, énfasis del autor)

Posteriormente, Ayala (2013, p. 237) afirma que

Las explicaciones científicas están basadas en evidencias procedentes de la examinación del mundo natural y confían exclusivamente en los procesos naturales para dar cuenta de los fenómenos naturales [...] La fe religiosa, en contraste, no depende de pruebas empíricas ni está sujeta a la posibilidad de rechazo basado en la evidencia empírica.

$\mathrm{Y}$ de manera concluyente argumenta que "Nuestro sistema educativo y nuestra sociedad como un todo resultan más beneficiados cuando enseñamos ciencia, no fe religiosa, en las clases de ciencias. Éste no es sino un paso en el esfuerzo de obtener el eslabón perdido de la alfabetización científica" (AYALA, 2013, p. 237). Al parecer, Ayala hace caso omiso de lo que planteó Dobzhansky en su tan mentado artículo: una defensa para entrelazar férreamente evolución y creación. Me parece que reconocer la importancia de la enseñanza y el aprendizaje de la evolución no debería sustentarse en el célebre DCSE.

En tal sentido, coincido con Gutiérrez (2009, p. 120, énfasis del autor) cuando sostiene:

Si bien consideramos que el tópico religioso puede ser trabajado debido a que pueden existir obstáculos transversales relacionados con el origen y la diversidad de la vida, resulta confuso plantear en un mismo plano explicativo discursos provenientes de la esfera religiosa y de la científica.

Como se ha expuesto, Dobzhansky puso esos dos ámbitos contradictorios en un mismo plano y eso ha tenido implicaciones funestas para el aprendizaje y la enseñanza de la evolución. Así las cosas, reitero que las lecciones de Dobzhansky no son las más idóneas para orientar la enseñanza de la biología evolutiva:

Tengamos presente que la biología que se enseña persiste en la actitud de negar la monumental presencia de la historia que constituye todo lo 
vivo. Así, lo vivo sigue perteneciendo al campo de lo dado, de lo óptimo, de lo equilibrado, de lo divino. En fin, se trata, nos parece, de poner la enseñanza de la biología en este mundo. (GUTIÉRREZ, 2009, p. 202)

Nótese que el reclamo por reconocer el valor de la historia para entender la biología (y en particular la evolución) es opuesto a asumir el origen y devenir de los organismos desde postulados religiosos: o nos comprometemos con la contingencia de la historia o lo hacemos con los designios de dios. Para lograr el cometido de Gutiérrez, con el que estoy totalmente de acuerdo, hay que llevar a cabo muchas acciones, una de las cuales es empezar a desterrar los dogmas, como el DCSE, de la biología y su enseñanza.

\section{Conclusión: hacia la "prescindibilidad" de los dogmas en la Biología y su Enseñanza}

Quien, en los albores del siglo XXI, se declare darwinista y cite desprevenidamente la frase de Dobzhansky (1973), como epígrafe y/o como una manera de demostrar la importancia de la historia evolutiva, estaría cayendo en una flagrante contradicción, pues no se pueden hacer las dos cosas a la vez. Mi objetivo central, al escribir este artículo, ha sido llamar la atención sobre este punto. Si leemos con cuidado el texto de Dobzhansky (1973) y otros de sus escritos (en especial algunas cartas), lo pensaríamos dos veces antes de traer a colación esa trillada frase y consentir con ella. Vimos cómo otros dogmas de la biología tuvieron una existencia efímera, lo cual no ha ocurrido con el DCSE, debido, principalmente, a que tiene muchos seguidores (y usuarios), pero, ¿éstos son conscientes de su origen y de sus implicaciones? Así como la historia evolutiva nos permite establecer relaciones de ancestría, la historia de las ideas (y de los dogmas y eslóganes) nos puede ayudar a comprender de dónde vienen los postulados con los que nos comprometemos. ¿Es darwinista el DCSE? Para nada.

Gould (1982, p. xvii), citando un pasaje de la segunda edición del El origen del hombre, afirma que Darwin tenía dos objetivos en mente: demostrar que la evolución es un hecho (en palabras de Darwin: "que las especies no han sido creadas separadamente" y poner de manifiesto que ésta ocurre debido al proceso de selección natural. Como es bien sabido, ambas propuestas fueron, y siguen siendo, duramente criticadas. En el fragmento que cita Gould (1982, p. xvii), Darwin concluye:

[...] Si he errado en dar a la selección natural un gran poder, lo que estoy muy lejos de admitir, o en haber exagerado su poder, lo cual es en sí mismo probable, al menos, como espero, he hecho un buen servicio al ayudar a echar abajo el dogma de las creaciones separadas. (énfasis nuestro) 
Es paradójico que Gould utilice este pasaje de Darwin para iniciar la introducción de la $3^{a}$ edición del libro clásico de Dobzhansky $(1982)^{24}$. La paradoja consiste en que Gould reconoce la importancia de Dobzhansky en el establecimiento y el desarrollo del pensamiento evolutivo (darwiniano), pero no dice nada de sus creencias creacionistas, las cuales son un obstáculo para complementar el logro de Darwin en su afán por derrumbar el dogma del creacionismo. Tal vez, Gould no conoció esa otra faceta (creacionista) de Dobzhansky... o decidió no aludir a ella. La paradoja se hace más evidente si leemos al propio Gould (1982, p. xvii):

[Darwin] sintió que había triunfado en su primer objetivo; virtualmente todas las personas educadas aceptan ahora el hecho de la evolución [...] Darwin temía que la gente pudiera confundir hecho con mecanismo [...] Al inspeccionar hoy la literatura del así llamado 'creacionismo científico', comprendemos que el temor de Darwin era juicioso y no paranoico; debido a que estos modernos antediluvianos están haciendo propaganda al distorsionar intencionadamente nuestros sanos debates contemporáneos acerca de los mecanismos evolutivos, al hacer afirmaciones falsas: que incluso los científicos han empezado a cuestionar el hecho de la evolución en sí mismo.

Lo que Gould (1982) no advierte (o no quiere advertir) es que Dobzhansky no sólo estaba del lado de los evolucionistas, sino que también pertenecía a las filas de los "modernos antediluvianos creacionistas". Así pues, este último grupo tenía en parte la razón, ya que Dobzhansky, con sus especulaciones filosófico-religiosas, estaba poniendo en duda el hecho de la evolución, si entendemos por esto lo que expresó Darwin y que cité más arriba: "demostrar que no es cierto el dogma de la creación de las especies".

Para sustentar esta afirmación, traeré a colación otras frases de Dobzhansky que podrían dejar sin aliento a todo el que siga creyendo que este autor era un férreo darwinista, y que por ello decida emplear su trillada frase (el DCSE) a modo de epígrafes y otros menesteres. En una carta que Dobzhansky le escribió al filósofo e historiador de la ciencia John Greene, en noviembre de 1961, dice lo siguiente:

Me niego a abstenerme de hablar de progreso, mejoramiento y creatividad. ¿Por qué debería hacerlo? En evolución algunos organismos progresaron y mejoraron, y permanecen vivos, otros fallaron en ello y se han extinguido. Algunas adaptaciones son mejores que otras -para los organismos que las poseen, ellas son mejores para la sobrevivencia que para la muerte. Sí, la vida es un valor y un éxito, la muerte carece de valor y es un fracaso. De este modo, algunos cambios evolutivos son mejor que otros [...] Me temo que las frases de arriba pueden ser

\footnotetext{
${ }^{24}$ Genetics and the origin of species, cuya primera edición es de 1937.
} 
malentendidas - no dudo que en algún nivel la evolución, como todo lo demás en el mundo, es una manifestación de la actividad de Dios. Todo lo que digo es que como científico no observo nada que probaría esto. En breve, como científicos, Laplace y yo mismo, 'no necesitamos esa hipótesis', pero como ser humano jsi necesito esa bipótesis! (DOBZHANSKY, 1961 apud ARAÚJO, 2000, p. 34, énfasis nuestro)

Por si queda alguna sombra de duda acerca de la posición de Dobzhansky, leamos lo que dice en esa misma carta, pero previamente:

Yo soy cristiano [...] La evolución (cósmica + biológica + humana) camina en dirección a alguna cosa, que esperamos sea hacia alguna Ciudad de Dios. Esa creencia no nos ha sido impuesta por los descubrimientos científicos, pero, si quisiéramos (y si no quisiéramos), podremos ver en la naturaleza las manifestaciones de Omega ${ }^{25}$, o su campo creativo (¿no se escribe esto con letras mayúsculas?) o simplemente de Dios... No puedo creer que Dios se torne, de vez en cuando, una enzima particularmente poderosa. No veo cómo evitar pensar que Dios actúa no en las adaptaciones de intervenciones milagrosas, sino en todos los eventos, significativos e insignificantes, espectaculares y corrientes. (DOBZHANSKY, 1961 apud OLIVEIRA, 1998, p. 57-58, énfasis nuestro)

Desde este punto de vista, el DCSE es totalmente falso, ya que Dobzhansky erró al decir que para que algo tenga sentido en biología ello debe estar iluminado por el faro de la evolución. En ese sentido, una respuesta a la pregunta del título de este artículo es un no rotundo. Claro, si entendemos por evolución lo que Dobzhansky expresó en diferentes textos: un proceso progresivo, de mejora y dirigido por la mano de dios. Pero si, por el contrario, asumimos la evolución de una manera similar a como lo hizo Darwin, como un proceso contingente, natural y carente de intencionalidad, el asunto toma otro rumbo. Por supuesto que desde esta perspectiva tampoco podríamos sostener que nada tiene sentido en la biología si aquello no está sustentado desde el marco conceptual de la teoría evolutiva. Sería más sensato decir que todo en biología puede comprenderse mejor si nos apoyamos en la evolución (CASTRO, 2009, p. 20).

Ya vimos que uno de los objetivos de Darwin era desterrar cualquier poder sobrenatural de la explicación del origen, la diversificación y la extinción de la naturaleza viviente; y en

\footnotetext{
${ }^{25}$ Fue Teilhard de Chardin quien inventó la frase "hombre Omega" y la usó para describir un ser futuro, que se elevará sobre nosotros, tanto espiritual como intelectualmente, cuyo destino es completar el plan divino para este planeta por medio de la perfección en el nivel mental. Por otra parte, el "Punto omega", término también acuñado por él, describe el cenit de la evolución de la consciencia, considerándolo como el fin último de la misma (MIDGLEY, 1985, p. 72). Vemos, de esta manera, otras conexiones no explícitas entre el pensamiento de Dobzhansky y el del jesuita francés.
} 
eso tuvo éxito. Es desde este contexto que propongo abolir para siempre el DCSE. Además, hay que tener en cuenta que la luz, para entender la evolución, es una mala metáfora, pues ésta tiene una fuente discernible y se desplaza en línea recta: ijusto como la entendía Dobzhanskyi ${ }^{26}$ En contraste, el único diagrama que usó Darwin en el Origen de las especies fue un árbol (que hoy denominamos filogenético), el cual es una manera más compleja de entender el proceso evolutivo. La teoría evolutiva nos ha enseñado que nuestra especie se halla en una rama del árbol, no en su cúspide (porque en esta perspectiva no tendría sentido hablar de punto culminante): el proceso que nos ha permitido hacer parte de ese árbol es contingente y natural, no guiado por fuerzas de otro mundo. Así pues, a pesar de las tergiversaciones y los dogmatismos para los que se ha usado, podemos decir con optimismo que la obra darwiniana no ha sido en vano.

Ciertamente, es fácil criticar a quienes han muerto, por lo que mis dardos no han estado dirigidos sólo a Dobzhansky, sino, sobre todo, a sus seguidores actuales, quienes usan acríticamente el DCSE. Hago un llamado particular a los maestros de biología, el auditorio al que Dobzhansky le propuso su famosa frase: ¿estamos dispuestos a perpetuarla, al menos sin discutir a fondo su pertinencia y sus implicaciones en la didáctica de la biología? Hemos visto que el DCSE no es tan transparente e inocuo como se ha supuesto, por lo que es hora de tomar cartas en el asunto, si queremos hacer un aporte a la enseñanza de la biología, entre otras cosas al empezar a "des-dogmatizarla". Ha quedado claro que el DCSE es más un obstáculo que una posibilidad para comprender el proceso evolutivo: Dobzhansky, con su eslogan, pretendió iluminarnos el camino, pero, por el contrario, el DCSE nos ha enceguecido con su luz resplandeciente. Sin duda, aún tenemos mucho que aprender del propio Darwin.

\footnotetext{
${ }^{26}$ Además de lo que Dobzhansky dijo en el artículo de 1973, podemos agregar otra frase suya, escrita en una carta a Greene: "Para mí [...] como para Teilhard, la evolución es una luz que brilla [...] y no tengo duda de que es una manifestación de la actividad de Dios” (DOBZHANSKY, 1961 apud OLIVEIRA, 1998, p. 58).
} 
Castro Moreno, J. A.

\section{Referencias}

ABRANTES, P. C. Introdução: o que é filosofia da biologia? In: ABRANTES, P. C. et al. Filosofia da biologia. Porto Alegre: Artmed, 2011. p. 11-36.

ARAÚJO, A. M. A influência de Theodosius Dobzhansky no desenvolvimento da genética no Brasil. Episteme, Porto Alegre, v. 3, n. 7, p. 43-54, 1998.

Imanência e transcendência na evolução biológica: a visão de Theodosius Dobzhansky. Episteme, Porto Alegre, n. 11, p. 21-36, 2000.

AYALA, F. J. Aspectos filosóficos. In: DOBZHANSKY, T. et al. Evolución. Barcelona: Omega, 1993, p. 472-513.

Scientific literacy and the teaching of evolution. Ludus Vitalis, México, v. 21, n. 39, p. 231-237, 2013. Disponible en: < http://www.ludusvitalis.org/textos/39/3915_ayala.pdf >. Visitado en: 30 sep. 2013.

BARAHONA, A. Historia de la genética humana en México 1870-1970. México: Universidad Nacional Autónoma de México, 2009.

BARAHONA, A.; AYALA, F. J. Theodosius Dobzhansky's role in the emergence and institutionalization of genetics in Mexico. Genetics, Bethesda, v. 170, n. 3, p. 981-987, 2005.

BIZZO, N.; EL-HANI, C. N. Darwin and Mendel: evolution and genetics. Journal of Biological Education, New York, v. 43, n. 3, p. 108-114, 2009.

BROMHAM, L. Does nothing in evolution make sense except in the light of population genetics? Biology \& Philosophy, Dordrecht, v. 24, n. 3, p. 387-403, 2009.

BURIAN, R. Nothing in biology makes sense except in the light of evolution (Theodosius Dobzhansky). In: . The epistemology of development, evolution, and genetics. New York: Cambridge University Press, 2005. p. 103-120.

CASTRO, J. A. La idea de contingencia histórica como eje central del darwinismo: una discusión en torno a la actualidad de Darwin. Bio-Grafía: escritos sobre la biología y su enseñanza, Bogotá, v. 2, n. 3, p. 84-106, 2009. Disponible en: <http://

revistas.pedagogica.edu.co/index.php/bio-grafia/article/view/284>. Visitado en: 09 sep. 2013.

CASTRO, J. A.; VALBUENA, E. O. ¿Qué biología enseñar y cómo hacerlo? Hacia una resignificación de la biología escolar. TED: Tecné, Episteme y Didaxis, Bogotá, n. 22, p. 126-145, 2007. Disponible en: <http://revistas.pedagogica.edu.co/index.php/TED/ article/view/385/387>. Visitado en: 30 sep. 2013.

CRICK, F. On protein synthesis. In: SYMPOSIA OF THE SOCIETY FOR EXPERIMENTAL BIOLOGY, 12., 1958. Proceedings of Meetings and Symposia... Cambridge: Cambridge University Press, 1958. p. 138-163.

DARWIN, C. El origen de las especies por medio de la selección natural. México: Universidad Nacional Autónoma de México, 2009. 
DAWKINS, R. El espejismo de Dios. Madrid: Espasa Calpe, 2007.

DOBZHANSKY, T. Genetics and the origin of species. 3. ed. New York: Columbia University Press, 1982.

Nothing in biology makes sense except in the light of evolution. The American Biology Teacher, Reston, v. 35, n. 3, p. 125-129, 1973. Disponible en: <http:// www.jstor.org/stable/4444260>. Visitado en: 30 sep. 2013.

DOBZHANSKY, T. et al. Evolución. Barcelona: Omega, 1993.

FOLGUERA, G.; GALLI, L. La extensión de la síntesis evolutiva y los alcances sobre la enseñanza de la teoría de la evolución. Bio-Grafía: escritos sobre la biología y su enseñanza, Bogotá, v. 5, n. 9, p. 4-18, 2012. Disponible en: <http:// revistas.pedagogica.edu.co/index.php/bio-grafia/article/view/1710>. Visitado en: 10 sep. 2013.

GOULD, S. J. Evolution and the triumph of homology, or why history matters. American Scientist, New Haven, v. 74, n. 1, p. 60-69, 1986. Disponible en: <http://www.jstor.org/ stable/27853941>. Visitado en: 30 sep. 2013.

Introduction. In: DOBZHANSKY, T. Genetics and the origin of species. 3 ed. New York: Columbia University Press, 1982. p. xvii-xxxix.

Wonderful life: the Burgess Shale and the nature of history. New York: W. W. Norton, 1989.

GRIFFITHS, P. E. In what sense does 'nothing make sense except in the light of evolution'? Acta Biotheoretica, Leiden, v. 57, n. 1-2, p. 11-32, 2009.

GUTIÉRREZ, A. Biología: la teoría de la evolución en la escuela. Buenos Aires: Biblos, 2009. (Colección Claves para la formación docente).

JACOB, F. La estatua interior. Barcelona: Tusquets, 1989.

JIMÉNEZ, M. P. La enseñanza y el aprendizaje de la biología. In: (Coord.).

Enseñar ciencias. Barcelona: Graó, 2003. p. 119-146.

KOHLER, R. Lords of the fly: Drosophila genetics and the experimental life. Chicago: The University of Chicago Press, 1994.

MARTÍNEZ, S.; BARAHONA, A. (Comp.). Historia y explicación en biología. México: Universidad Nacional Autónoma de México: Fondo de Cultura Económica, 1998.

MAYR, E. Por qué es única la biología: consideraciones sobre la autonomía de una disciplina científica. Buenos Aires: Katz, 2006.

MIDGLEY, M. Evolution as a religion: strange hopes and stranger fears. London: Methuen, 1985.

OLIVEIRA, D. L. Polêmicas recorrentes na síntese evolutiva. Episteme, Porto Alegre, v. 3, n. 6, p. 52-67, 1998. 
Castro Moreno, J. A.

OLIVEIRA, G.; PAGAN, A.; BIZZO, N. Evolución biológica: actitudes de estudiantes brasileños. Bio-Grafía: escritos sobre la biología y su enseñanza, Bogotá, v. 5, n. 9, p. 51-66, 2012. Disponible en: <http://revistas.pedagogica.edu.co/index.php/bio-grafia/article/ view/1713>. Visitado en: 12 sep. 2013.

RUIZ, R. et al. Enseñar y aprender biología evolutiva en el siglo XXI. Bio-Grafía: escritos sobre la biología y su enseñanza, Bogotá, v. 5, n. 9, p. 80-88, 2012. Disponible en: <http:// revistas.pedagogica.edu.co/index.php/bio-grafia/article/view/1715>. Visitado en: 14 sep. 2013.

STERELNY, K.; GRIFFITHS, P. Sex and death: an introduction to philosophy of biology. Chicago: The University of Chicago Press, 1999.

Artigo recebido em 01/04/13. Aceito em 28/08/13. 